NASA/CR—2003-211817

\title{
Comparison of On-Orbit and Ground Based Hollow Cathode Operation
}

Christian Carpenter

QSS Group, Inc., Cleveland, Ohio 
Since its founding, NASA has been dedicated to the advancement of aeronautics and space science. The NASA Scientific and Technical Information (STI) Program Office plays a key part in helping NASA maintain this important role.

The NASA STI Program Office is operated by Langley Research Center, the Lead Center for NASA's scientific and technical information. The NASA STI Program Office provides access to the NASA STI Database, the largest collection of aeronautical and space science STI in the world. The Program Office is also NASA's institutional mechanism for disseminating the results of its research and development activities. These results are published by NASA in the NASA STI Report Series, which includes the following report types:

- $\quad$ TECHNICAL PUBLICATION. Reports of completed research or a major significant phase of research that present the results of NASA programs and include extensive data or theoretical analysis. Includes compilations of significant scientific and technical data and information deemed to be of continuing reference value. NASA's counterpart of peerreviewed formal professional papers but has less stringent limitations on manuscript length and extent of graphic presentations.

- TECHNICAL MEMORANDUM. Scientific and technical findings that are preliminary or of specialized interest, e.g., quick release reports, working papers, and bibliographies that contain minimal annotation. Does not contain extensive analysis.

- CONTRACTOR REPORT. Scientific and technical findings by NASA-sponsored contractors and grantees.
- CONFERENCE PUBLICATION. Collected papers from scientific and technical conferences, symposia, seminars, or other meetings sponsored or cosponsored by NASA.

- SPECIAL PUBLICATION. Scientific, technical, or historical information from NASA programs, projects, and missions, often concerned with subjects having substantial public interest.

- TECHNICAL TRANSLATION. Englishlanguage translations of foreign scientific and technical material pertinent to NASA's mission.

Specialized services that complement the STI Program Office's diverse offerings include creating custom thesauri, building customized data bases, organizing and publishing research results ... even providing videos.

For more information about the NASA STI Program Office, see the following:

- Access the NASA STI Program Home Page at http://www.sti.nasa.gov

- E-mail your question via the Internet to help@sti.nasa.gov

- Fax your question to the NASA Access Help Desk at 301-621-0134

- Telephone the NASA Access Help Desk at 301-621-0390

- Write to:

NASA Access Help Desk

NASA Center for AeroSpace Information 7121 Standard Drive

Hanover, MD 21076 
NASA/CR-2003-211817

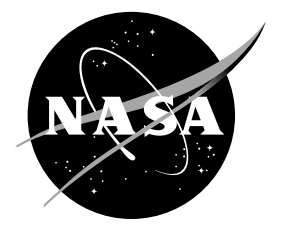

\section{Comparison of On-Orbit and Ground Based Hollow Cathode Operation}

Christian Carpenter

QSS Group, Inc., Cleveland, Ohio

Prepared for the

38th Joint Propulsion Conference and Exhibit

cosponsored by AIAA, ASME, SAE, and ASEE

Indianapolis, Indiana, July 7-10, 2002

Prepared under Contract NAS3-00145

National Aeronautics and

Space Administration

Glenn Research Center 
Available from

NASA Center for Aerospace Information 7121 Standard Drive

Hanover, MD 21076
National Technical Information Service 5285 Port Royal Road Springfield, VA 22100

Available electronically at http://gltrs.grc.nasa.gov 


\title{
Comparison of On-Orbit and Ground Based Hollow Cathode Operation
}

\author{
Christian Carpenter \\ QSS Group, Inc. \\ Cleveland, Ohio 44135
}

\begin{abstract}
$\underline{\text { ABSTRACT }}$
The Plasma Contactor Units (PCUs) were developed at NASA Glenn Research Center (GRC) and Boeing for charge control on board the International Space Station (ISS). Since the first ignition of a PCU on 10/16/2000 over 3,900 hours of operation have been demonstrated on a single unit. In order to guarantee that the PCUs' hollow cathode assemblies (HCAs), which emit the electrons used for charge control, would satisfy the life requirement of 18,000 hours, a ground based hollow cathode life test program was initiated at GRC. The life test program aimed at 27,000 hours of operation on a single unit to demonstrate the industry standard 1.5 times operational life requirement. As of this printing, over 18,000 hours of operation have been accumulated on a single hollow cathode. By comparing the data received from the on-orbit HCAs to the data obtained for the life test cathodes, a comparison may be drawn to determine if the on-orbit HCAs are operating normally, with a final goal of predicting lifetime. Based on the data taken thus far, it can be concluded that the on-orbit HCAs are operating within their design specifications.
\end{abstract}

\section{$\underline{\text { INTRODUCTION }}$}

The International Space Station (ISS) high voltage solar arrays deliver output voltages of $140 \mathrm{~V}$ to $160 \mathrm{~V}$. The electrical configuration of the ISS and the plasma current balance may cause the station to float at voltages predicted to be as much as $120 \mathrm{~V}$ below the ambient space plasma if no charge control device is used. If large negative floating potentials are present, the ISS could react with ambient space plasma. These reactions could include arcing and sputter erosion. ${ }^{1,2}$

The development of a plasma contactor for charge control aboard a space station began in 1992 with the United States' Space Station Freedom plasma contactor project at the NASA Glenn Research Center (GRC). The information and research from this program was carried over into the design of the International Space Station (ISS) plasma contactors in 1994. Hollow cathodes were chosen for this application due to their efficient, variable, and rapid emission of high electron currents. ${ }^{1}$

The plasma contactor units (PCUs), shown in Figure 1, aboard the ISS use a hollow cathode assembly (HCA), shown in Figure 2, to generate electrons used for ISS charge control. To verify that the HCAs are capable of completing their designated mission, a life test was started at NASA Glenn Research Center (GRC) in $1994 .^{3}$ The goal of the test is to demonstrate $27,000 \mathrm{hrs}$ of operation on a single HCA, which is 1.5 times the life requirement of the on-orbit HCAs. In addition to the life requirement, testing has been performed on the effects of ignition on hollow cathode performance. The data taken from this test should provide insight into the operation of the on-orbit HCAs and aid in problem diagnosis as well as life estimation.

The first two plasma contactor units (PCUs) were delivered aboard the shuttle Discovery in October of 2000 by the crew of STS-92. Two PCUs are used to ensure full redundancy, and they are co-located on the Z1 truss, shown in Figure 3, of the ISS in the area marked on Figure 4. The first ignition of a PCU aboard the ISS occurred on October 16, 2000.

\section{PLASMA CONTACTOR REQUIREMENTS}

Three main requirements were instituted for the design of the ISS PCUs. First, each PCU must control the ISS structure floating potential at all points on the station to $\pm 40 \mathrm{~V}$ of the space plasma potential. The effect of $\mathrm{v} \times \mathrm{B}$ charging as the ISS moves through the Earth's magnetic field tightens this requirement to $\pm 20 \mathrm{~V} .{ }^{4,5}$ Next each $\mathrm{HCA}$ is restricted to emit a maximum electron current of $10 \mathrm{~A}$ at no more than $20 \mathrm{~V}$. Finally, the PCU must be able to operate for no less than 18,000 hours, which is based on the amount of propellant in the PCU.

In order to extend the operational life of the PCU an additional mode of operation was suggested, in which the PCU operates only during periods of active ISS charging. In order to ensure operation in this mode, the PCU was also required to be capable of 6000 ignitions with no less than $99 \%$ reliability. ${ }^{4}$ 


\section{GROUND BASED TEST OPERATION}

The ground based testing of flight type HCAs included testing four hollow cathodes. These cathodes are herein called life test cathodes and labeled HCA003, HCA006, HCA010, and HCA013. The cathodes were tested in a configuration designed to simulate the conditions predicted to exist on the ISS. ${ }^{3}$ The test began July 7, 1994 with HCA006. HCA006 was removed in 1996 for destructive analysis after 8000 hours of operation. ${ }^{6}$ Since the beginning of the ground based life test, 18,873 hours have been demonstrated on HCA013. HCA010 has operated for 15,876 hours and has demonstrated 4,424 ignitions. There have been no failures of the cathodes under test. HCA013 has successfully exceeded the lifetime requirement, and will be tested until the qualification requirement of 27,000 hours is reached. The current status of the life test cathodes can be seen in Table I. The life test cathodes operate with 40 minutes of 3.0 A electron current to the anode. This mode of operation is herein called "Diode Mode". This operation is followed by 50 minutes of 2.5 A electron current to a close proximity bias electrode. This mode of operation is herein called "Triode Mode". The cyclic operation is designed to mimic the 90-minute orbit of the ISS, which consists of 40 minutes of shade, at which time the arrays are not collecting current (simulated by diode mode), followed by 50 minutes of sunlight, during which time the solar arrays are collecting current (simulated by triode mode).

\section{ON-ORBIT OPERATION}

The fist two PCUs (herein called flight cathodes and labeled PCU1 and PCU2) are currently still in operation aboard the space station. Table II shows the current status of each flight cathode. Though originally designed for continuous operation, these units operate only during extra-vehicular activities (EVAs), shuttle docking, or as deemed necessary. Typical discharge currents and anode voltages for these units are shown in Figures 5 and 6. Discharge current, which is the return current form the space plasma, ranges from $0.02 \mathrm{~A}$ to 0.05 A with voltages ranging from $12.5 \mathrm{~V}$ to $15 \mathrm{~V}$. Figure 5 shows that the discharge currents on orbit are substantially lower than the life test triode mode emission current of $2.5 \mathrm{~A}$, this is due to the fact that all of the ISS solar arrays have not all been installed, and therefore the ISS is not collecting as much current as previously predicted.

\section{DATA ANALYSIS METHOD}

Due to the large amount of data taken during the life test and the ISS, a program was needed that could handle formatting, searching, and plotting millions of data points. A database program was chosen as the analysis platform, as databases can handle large amounts of records and can be integrated with other programs.

Life test data are taken in increments of one to five minutes, which allows the entire test to be analyzed simultaneously. Currently the test data are split, based on the year of testing, but plans exist to create a database containing all life test data. Data are imported and formatted from comma-separated files generated by the test, after which the files are easily analyzed. Plots from this test are created by generating tables from the data by selecting records at regular intervals to create plots that do not exceed a maximum of 10,000 data points.

ISS data are taken in one-second increments. Thus, when downloaded from the ISS archive, the files are substantially larger than those of the life test. A typical ISS flight can create over 2 million data points. Due to the file size, the only practical way to analyze large amounts of ISS data is on a per flight basis. Data from each ISS flight are imported into a database from fixed width files. The imported table is then formatted into dates, times, or numbers. After formatting, data holes are filled by inserting the previous value of a parameter into the hole, creating a complete data set. This method was chosen because the ISS appears to create entries only when values change and complete data sets yield fewer errors when analyzed by the computer. Plots of this data are generated in the same method as life test plots. Cathode operating time is estimated by the database by testing for the "PCU on" condition and subtracting start from end times of this condition.

\section{COMPARISON OF ON-ORBIT TO GROUND BASED OPERATION}

Ignition times and anode voltages have been shown to be a good indicator of cathode health. In order to diagnose the health of the flight cathodes, their performance was compared to the performance of life test cathodes.

Ignition times for both life test and flight cathodes are shown in Table III. The listed ignition times begin with application of heater power. Ignition is completed when the anode voltage is less than the open circuit voltage. Life test cathode ignition times, plotted in Figure 7, show a span form 211 seconds to 400 seconds for the majority of the ignitions. HCA010 has long ignition times during the first few ignitions, but this may be related experimentation with ignition procedures. Geometric changes, barium depletion, and 
contamination, as well as other factors, can all cause increases in ignition time. Evolution of barium tungstate from long duration operation appears to be the main cause of ignition time increases. ${ }^{8}$ For life test cathodes, there does appear to be a trend of increasing ignition time with the number of ignitions.

The flight cathode ignition times span 210 seconds to 353 seconds. There is a slight rising trend, seen in Figure 8, which is consistent with the life test plot in Figure 7. After ignition 10, both life test and flight cathode ignition times fall in the $210 \mathrm{~s}$ to $350 \mathrm{~s}$ range, and there were no incidents of abnormally long ignition times.

As shown in Table II, flight cathode PCU1 has operated for 2742 hours. Based on this, a comparison between initial operation and operation at 3,000 hours was initiated. In order to make legible plots, only data for HCA006 and PCU2 are shown. Several long duration wear tests have shown that anode voltages begin to rise with operation time and oscillate after 500 to 1000 hours of operation. ${ }^{7-11}$ Several mechanisms have been speculated as the cause of these changes such as: geometric changes in the cathode ${ }^{9}$ (due to deposition, erosion, or sputtering), pressure changes, and thermochemistry ${ }^{8,12}$. To verify that no geometric changes are affecting the anode voltages of this test, the life test cathodes were inspected to verify their dimensions. The inspection consisted of using a pin gauge to manually inspect each cathode. Although the life test cathodes have accumulated thousands of hours of operation, no change was seen to the cathode orifice or keeper orifice as has been reported in similar tests. ${ }^{11}$

As shown in Figure 9 and 10, data from the first operation of life test and flight cathodes show a distribution in anode voltage between $11.5 \mathrm{~V}$ and $17 \mathrm{~V}$ for life test cathodes and $12.2 \mathrm{~V}$ to $16.2 \mathrm{~V}$ for the flight cathodes. The peaks shown in Figure 9 correspond to cathode operation in diode mode, which simulates the ISS shade condition, while the valleys correspond to operation in triode mode, which simulates the sunlight condition. Peaks and valleys for the flight cathode anode voltages correspond to the position of the ISS. The data from first operation verify that the anode voltages of the flight cathodes are on the same order as the life test cathodes during the beginning of cathode life.

Figure 11 and 12 show anode voltage plots for life test HCA006 and flight cathode PCU2 operating at approximately 3,000 hours. Anode voltages range from $11.5 \mathrm{~V}$ to $14 \mathrm{~V}$ for the life test cathode and $12.8 \mathrm{~V}$ to 13.5 V for the flight cathode. Like the beginning of life data, the flight cathodes do not show peaks and valleys as seen in the life test data. The data from 3,000 hours show that, while the patterns appear different, the anode voltage ranges are similar. Since both of the flight cathodes and the life test cathodes are operating with similar maximum and minimum voltages, it should be possible to use data taken from the ground based life test to simulate operation of flight cathodes.

\section{CONCLUSIONS}

After comparing the ignition times and anode voltages of the ISS HCAs to the HCAs used in the ground based life test at GRC, it can be concluded that all cathodes are operating within design specifications and demonstrate similar anode voltages and ignition times. Anode voltages are in the same range at the beginning of life and after 3,000 hours. Ground tests of HCAs operating for periods of 18,000 hours are continuing to operate without incident. These results indicate that the ISS HCAs should continue to exhibit stable operation and ignite reliably.

\section{REFERENCES}

1. Patterson, M.J., et. al., "Plasma Contactor for Space Station Freedom," AIAA Paper No. 93-2228, June 1993.

2. Patterson, M.J., et. al., "Plasma Contactor Development for Space Station," IEPC Paper No. 93246, September 1993.

3. Soulas, G.C., "Multiple Hollow Cathode Wear Testing for the Space Station," AIAA Paper No. 943310, June 1994.

4. Patterson, M.J., et. al., "Space Station Cathode Design, Performance, and Operating Specifications," NASA TM-1998-206529, May, 1998.

5. Kovaleski, S.D., and Patterson, M.J., "Correlation of Hollow Cathode Assembly Plasma Contactor Data from Ground Testing and In-Space operation on the International Space Station," IEPC Paper No. 252, October, 2001.

6. Soulas, G.C., and Sarver-Verhey, T.R., "International Space Station Cathode Life Test," IEPC Paper No. 166, August, 1997.

7. Verhey, T.R. and MacRae, G.S., "Requirements for Long-Life Operation of Inert Gas Hollow Cathode - Preliminary Results," AIAA Paper No. 2586, July 1990.

8. Sarver-Verhey, T.R. “28,000 Hour Xenon Hollow Cathode Life Test Results," NASA CR 97206231, November 1997.

9. Zakany, J. and Pinero, L., "Space Station Cathode Ignition Test Status at 32,000 Cycles," IEPC Paper No. 167, August, 1997. 
10. Sarver-Verhey, T.R., "Continuing Life Test of a Xenon Hollow Cathode for a Space Station Plasma Contactor," NASA CR 94-195401, November, 1994.

11. Brophy, J.R. and Garner, C.E., "Tests of High Current Hollow Cathodes for Ion Engines," AIAA Paper No. 88-2913, July, 1988.
12. Kovaleski, S.D., "Life Model of Hollow Cathodes Using a Barium Calcium Aluminate Impregnated Tungsten Emitter," IEPC Paper No. 276, October, 2001.

Table I - Status of Life Test Cathodes

\begin{tabular}{|c|c|c|c|}
\hline Unit & $\begin{array}{c}\text { Accumulated } \\
\text { Hours }\end{array}$ & $\begin{array}{c}\text { Accumulated } \\
\text { Ignitions }\end{array}$ & Status \\
\hline HCA003 & 12414.6 & 38 & Under Test \\
\hline HCA006 & 8029.8 & & $\begin{array}{c}\text { Disassembled } \\
\text { for Analysis }\end{array}$ \\
\hline HCA010 & 15876.1 & 4424 & Under Test \\
\hline HCA013 & 18873.2 & 59 & Under Test \\
\hline
\end{tabular}

Table II - Status of Flight Cathodes

\begin{tabular}{|c|c|c|}
\hline Unit & $\begin{array}{c}\text { Accumulated } \\
\text { Hours } \\
\text { (Estimated) }\end{array}$ & $\begin{array}{c}\text { Accumulated } \\
\text { Ignitions }\end{array}$ \\
\hline PCU1 & 2742 & 29 \\
\hline PCU2 & 3956 & 25 \\
\hline
\end{tabular}


Table III - Ignition Times

\begin{tabular}{|c|c|c|c|c|c|}
\hline \multirow{2}{*}{$\begin{array}{c}\text { Ignition } \\
\text { Number }\end{array}$} & \multicolumn{5}{|c|}{ Ignition Times, sec } \\
\hline & PCU1 & PCU2 & HCA003 & HCA010 & HCA013 \\
\hline 1 & 210 & 211 & & 855 & \\
\hline 2 & 224 & 211 & & 422 & 340 \\
\hline 3 & 263 & 211 & 421 & 275 & 317 \\
\hline 4 & 215 & 210 & 421 & 398 & 250 \\
\hline 5 & 210 & 270 & 245 & 520 & 276 \\
\hline 6 & 220 & 211 & 260 & 460 & 313 \\
\hline 7 & 243 & 241 & 421 & 517 & 273 \\
\hline 8 & 227 & 257 & 223 & 406 & 276 \\
\hline 9 & 305 & 251 & 256 & 354 & 264 \\
\hline 10 & 265 & 233 & 255 & 225 & 280 \\
\hline 11 & 242 & 247 & 274 & 258 & 273 \\
\hline 12 & 246 & 250 & 230 & 299 & 252 \\
\hline 13 & 256 & 347 & 303 & 290 & 268 \\
\hline 14 & 335 & 256 & 320 & 300 & 260 \\
\hline 15 & 264 & 224 & 316 & 320 & 268 \\
\hline 16 & 294 & 353 & 258 & 312 & 253 \\
\hline 17 & 212 & 236 & 329 & 320 & 239 \\
\hline 18 & 211 & 265 & 217 & 277 & 267 \\
\hline 19 & 243 & 280 & 277 & 306 & 227 \\
\hline 20 & 291 & 260 & 270 & 348 & 211 \\
\hline 21 & 318 & 252 & 253 & 348 & 240 \\
\hline 22 & 230 & 265 & 249 & 306 & 239 \\
\hline 23 & 226 & 256 & 246 & 295 & 263 \\
\hline 24 & 234 & 212 & 260 & 279 & 241 \\
\hline 25 & 252 & 270 & 281 & 295 & 276 \\
\hline 26 & 293 & & 283 & 269 & 216 \\
\hline 27 & 266 & & 302 & 292 & 293 \\
\hline 28 & 290 & & 270 & 274 & 306 \\
\hline 29 & 224 & & 261 & 358 & 248 \\
\hline 30 & & & 709 & 311 & 234 \\
\hline & & & & & \\
\hline
\end{tabular}




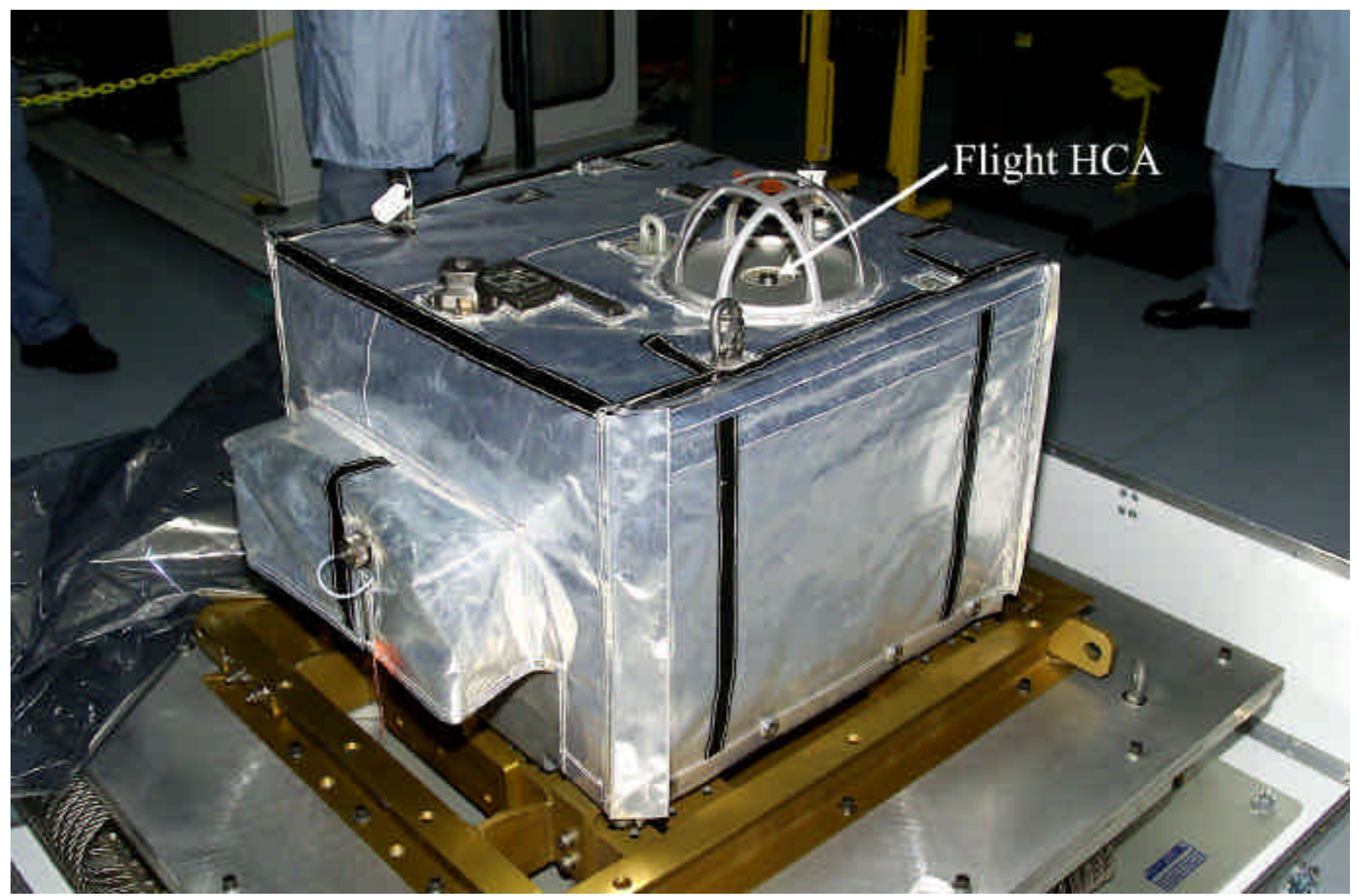

Figure 1 - Plasma Contactor Unit

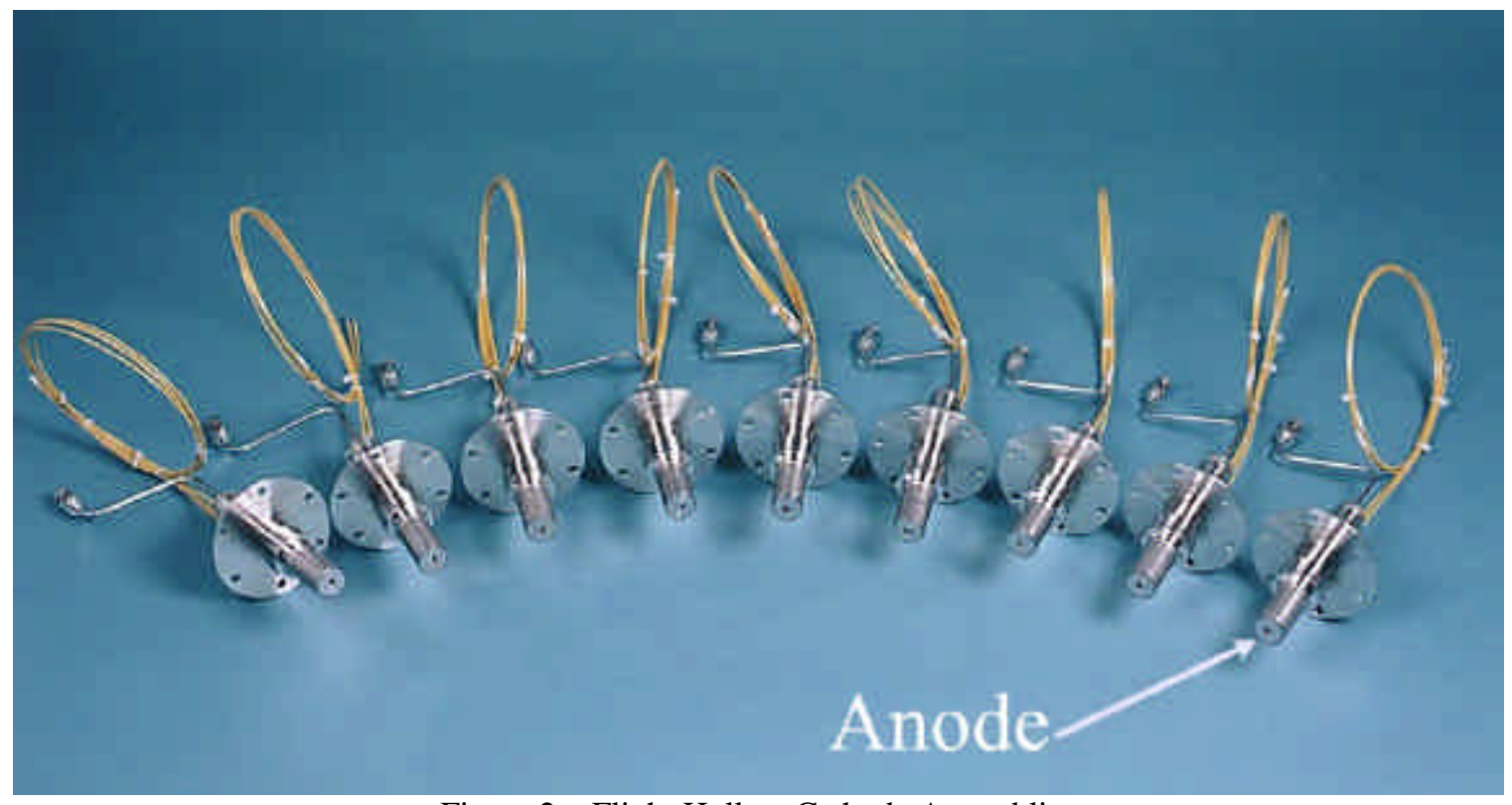

Figure 2 - Flight Hollow Cathode Assemblies 


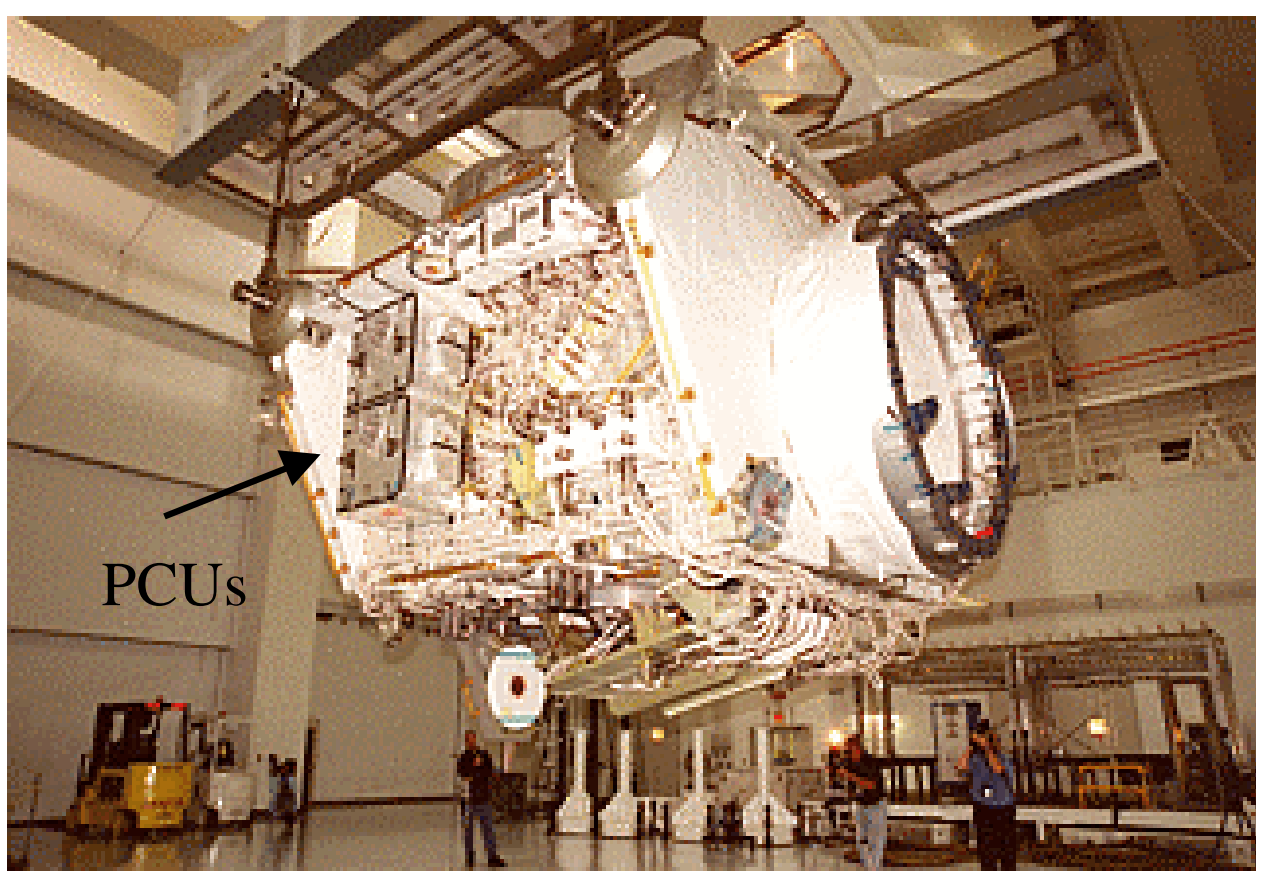

Figure 3 - Plasma Contactors on the Z1 Truss

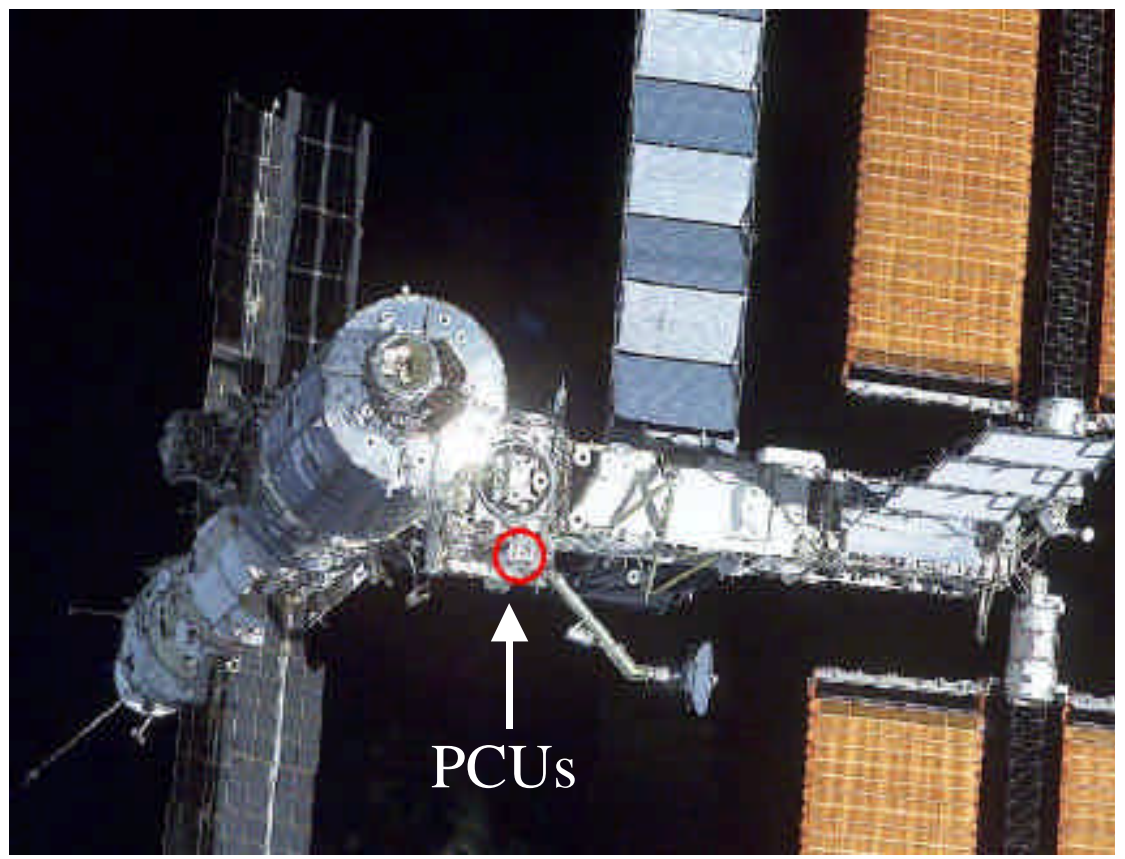

Figure 4 - Plasma Contactor Location on the ISS 
ISS313F

- Discharge Current - PCU 1 · Discharge Current - PCU 2

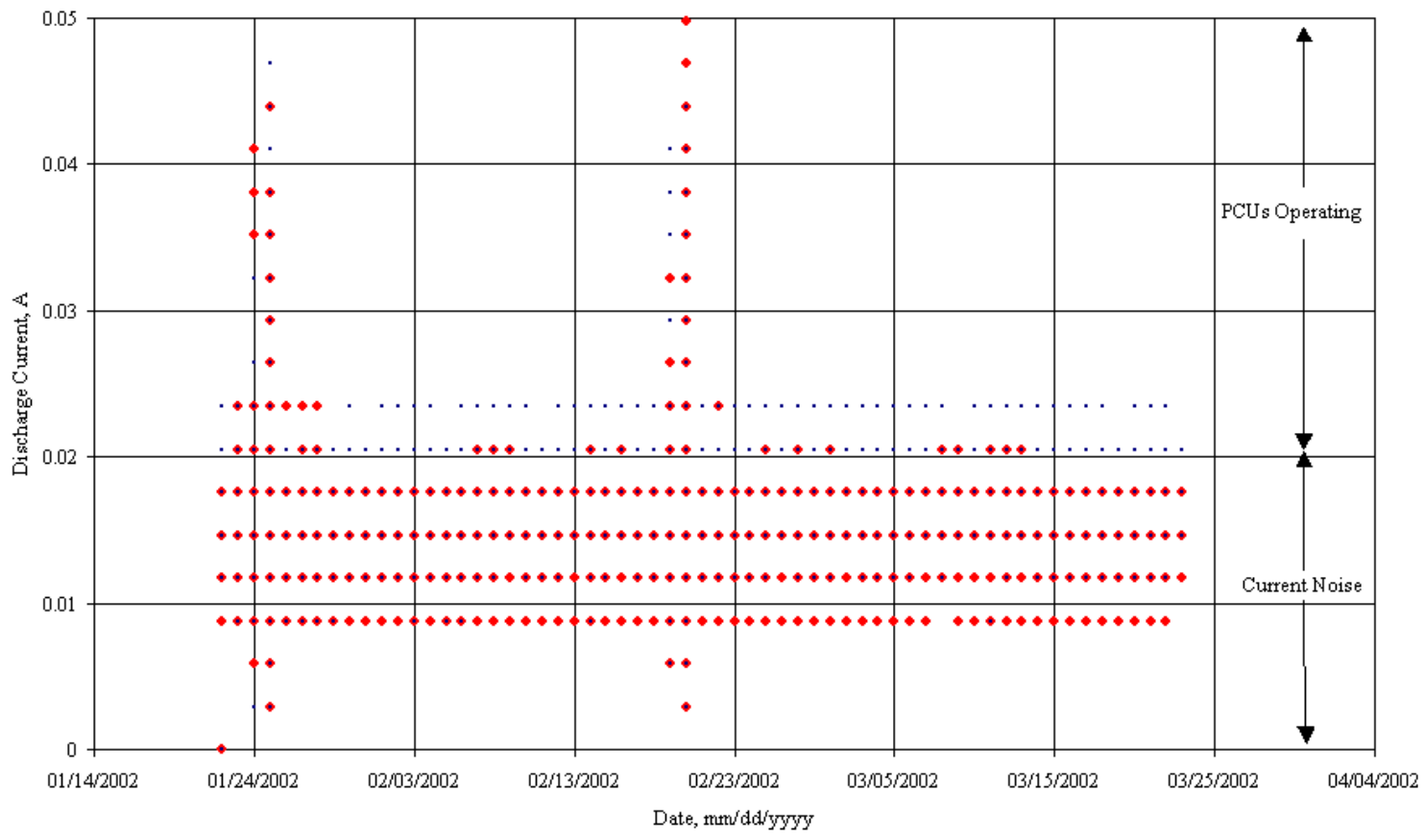

Figure 5 - PCU Discharge Current vs. Day for ISS Flight 313F

ISS313F

- Anode Voltage - PCU 1 - Anode Voltage - PCU 2

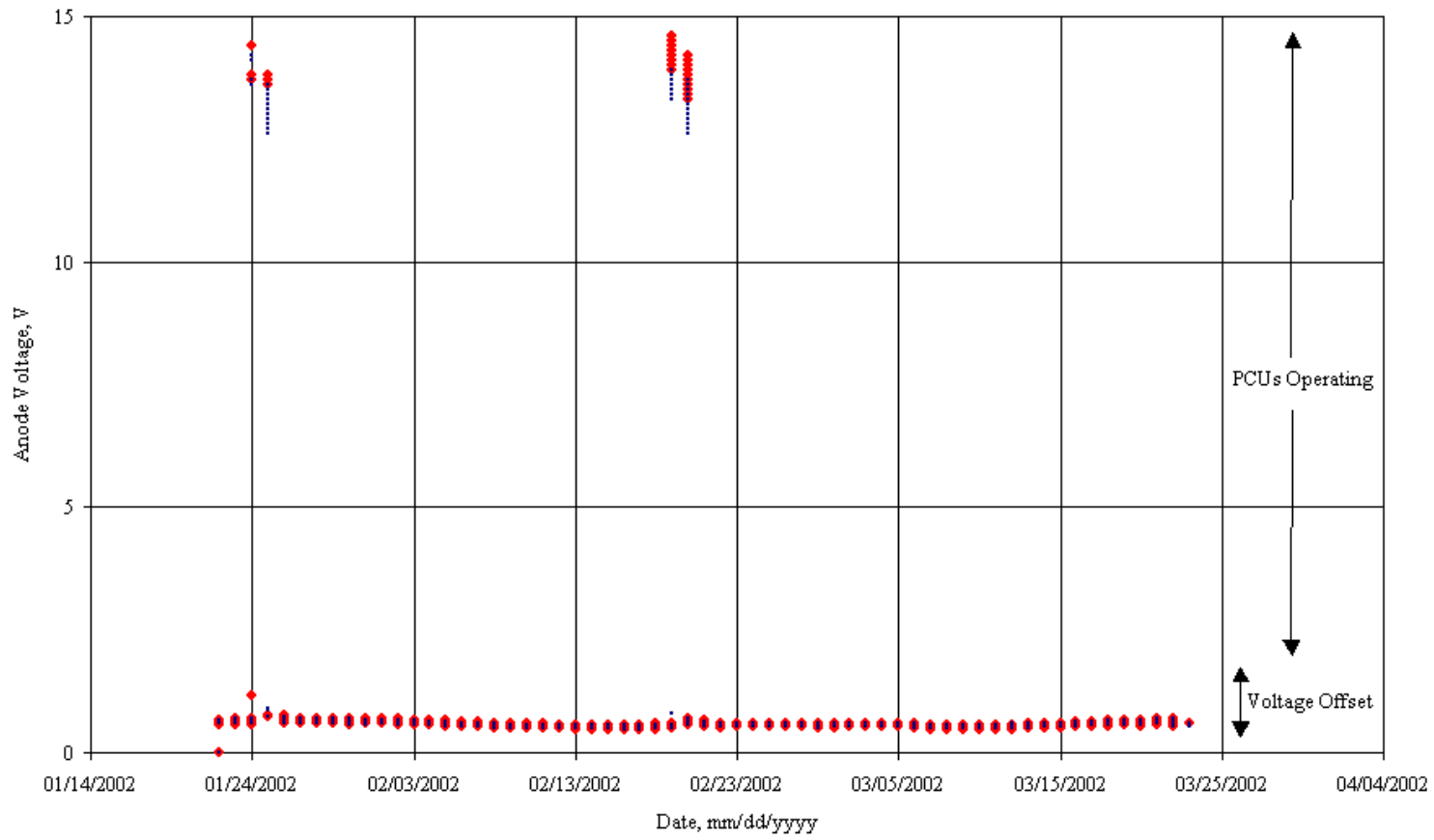

Figure 6 - PCU Anode Voltage vs. Day for ISS Flight 313F 


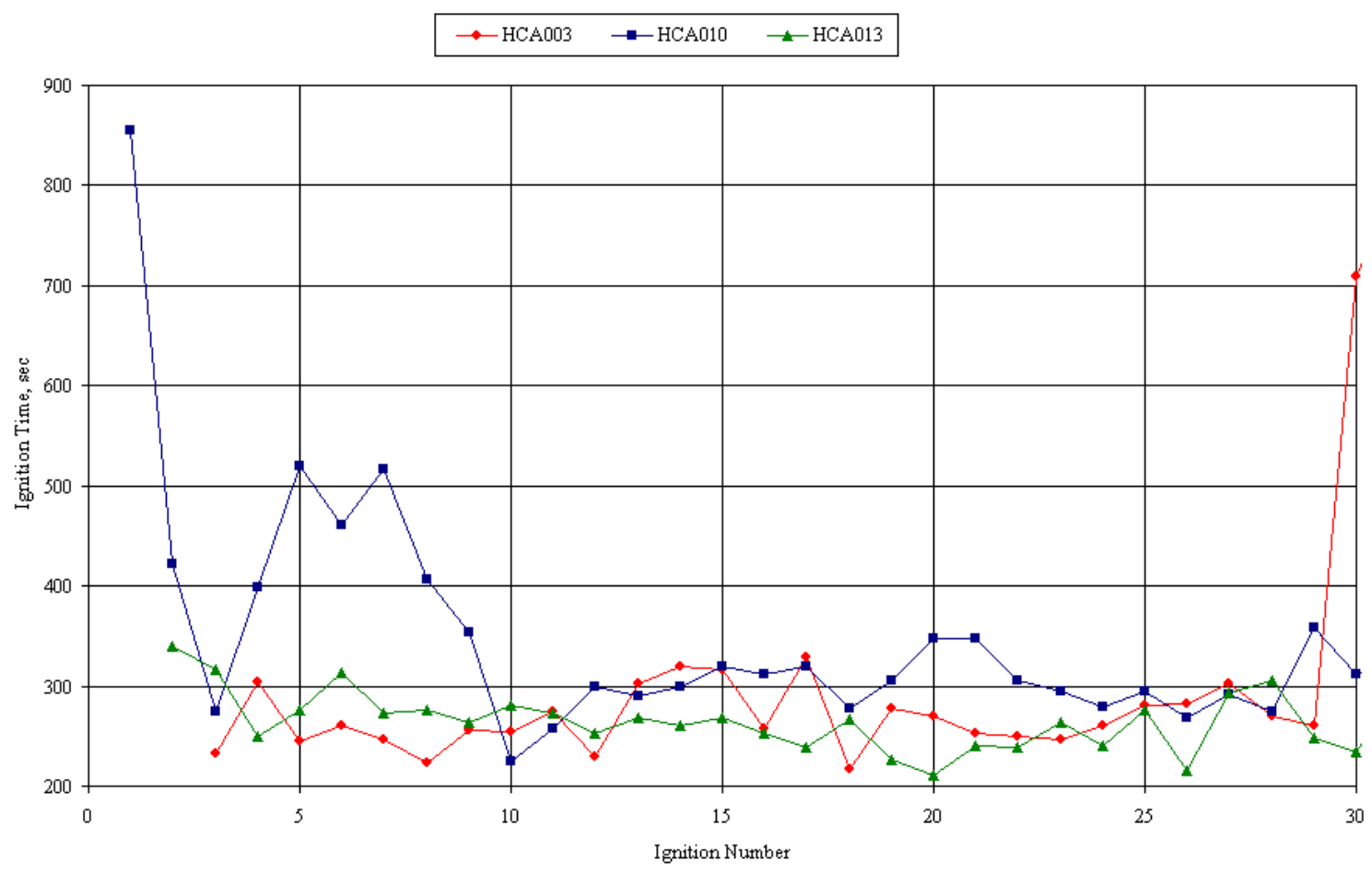

Figure 7 - Life Test Hollow Cathode Assembly Ignition Times

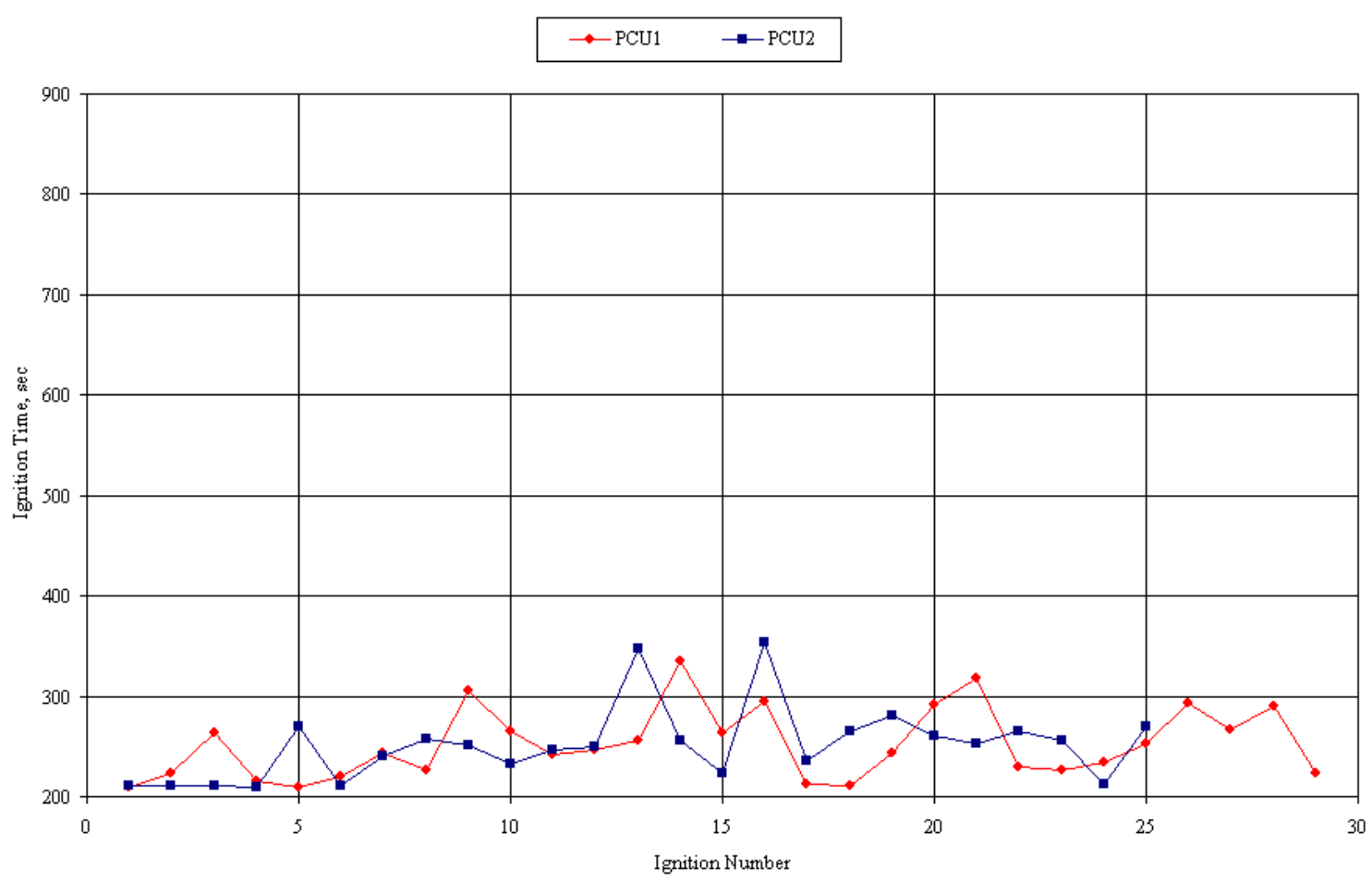

Figure 8 - Flight Hollow Cathode Assembly Ignition Times 


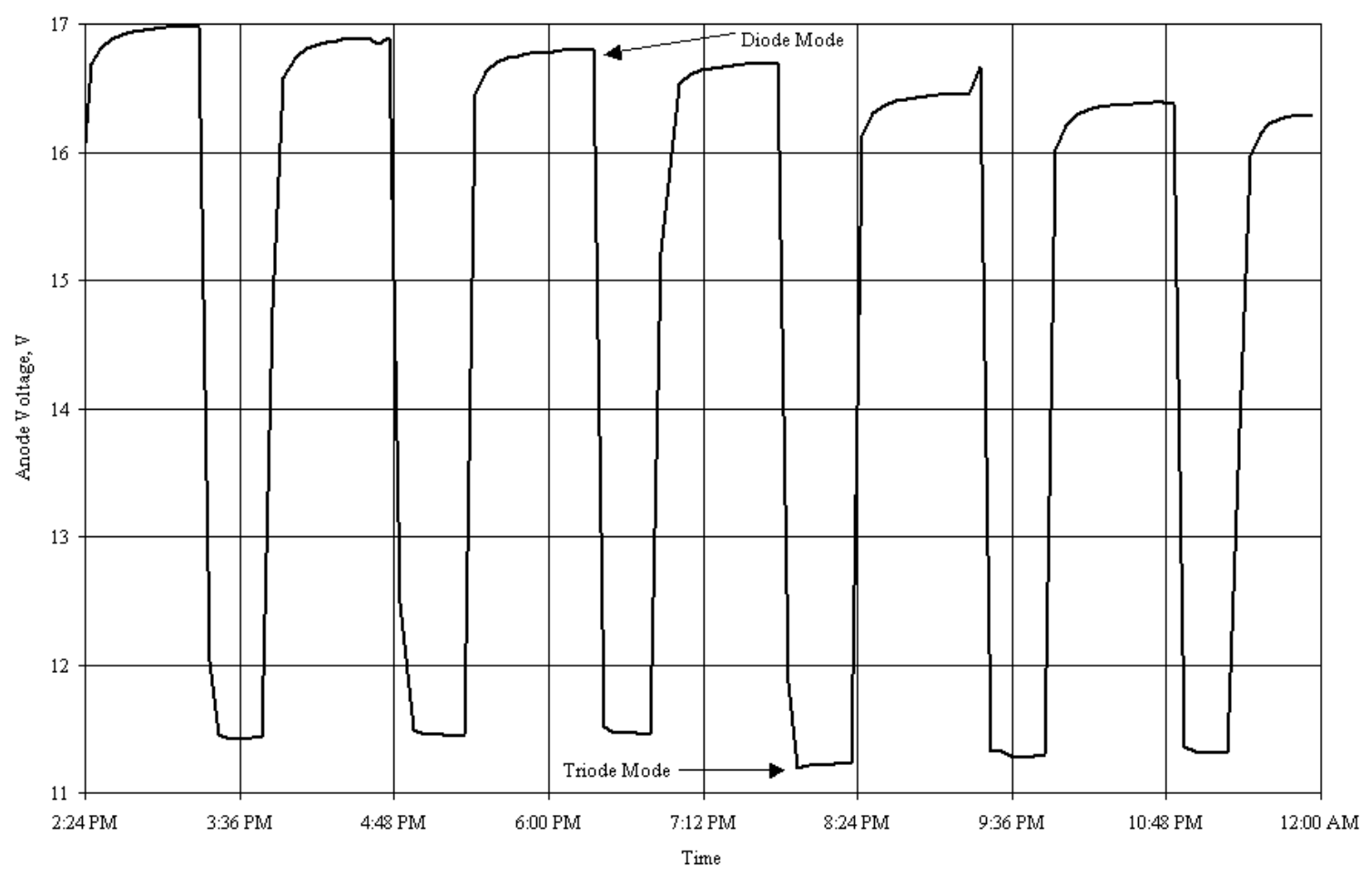

Figure 9 - HCA006 Anode Voltage During Initial Operation on 07/08/1994

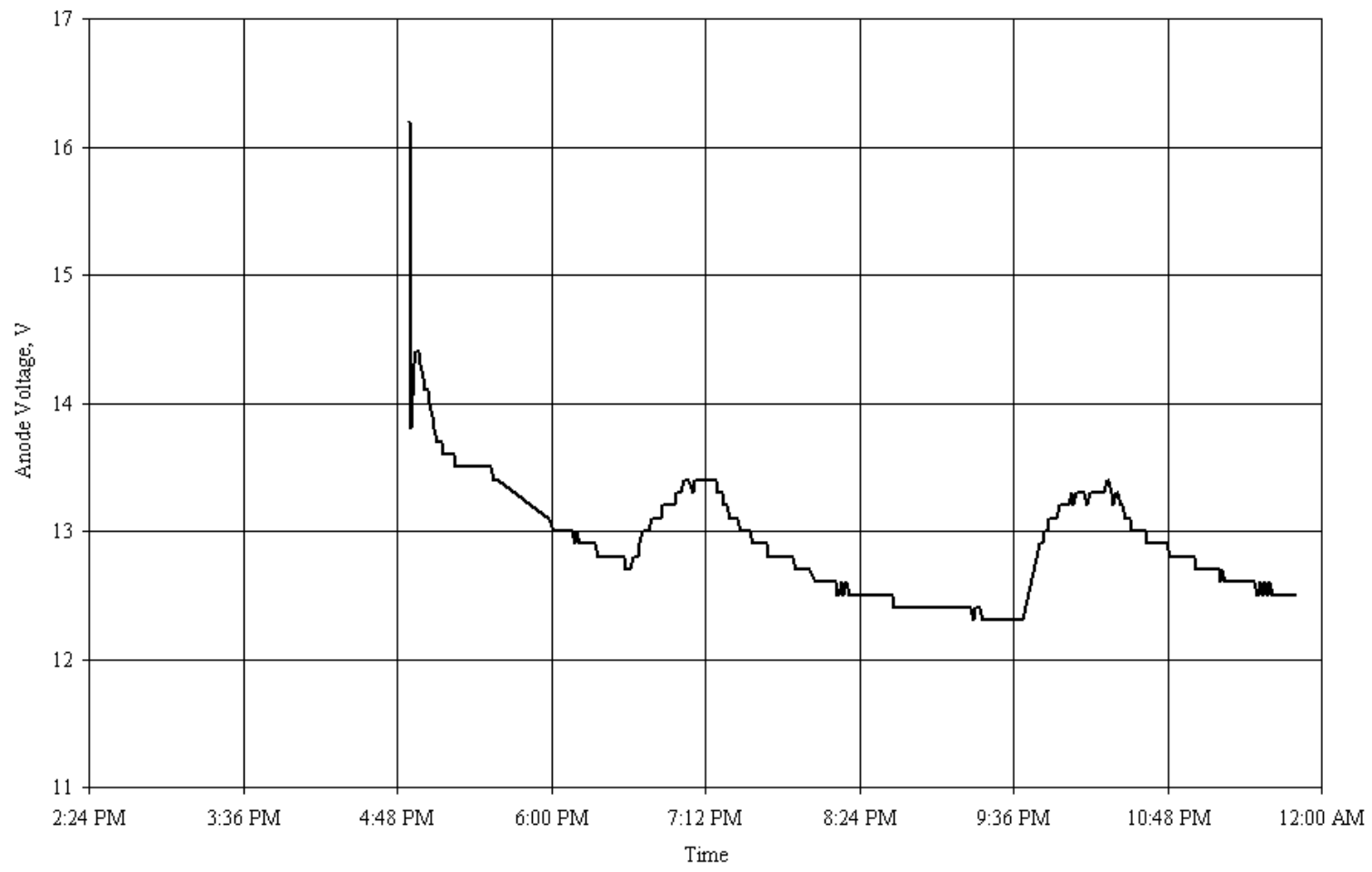

Figure 10 - PCU2 Anode Voltage During Initial Operation on 11/17/2000 


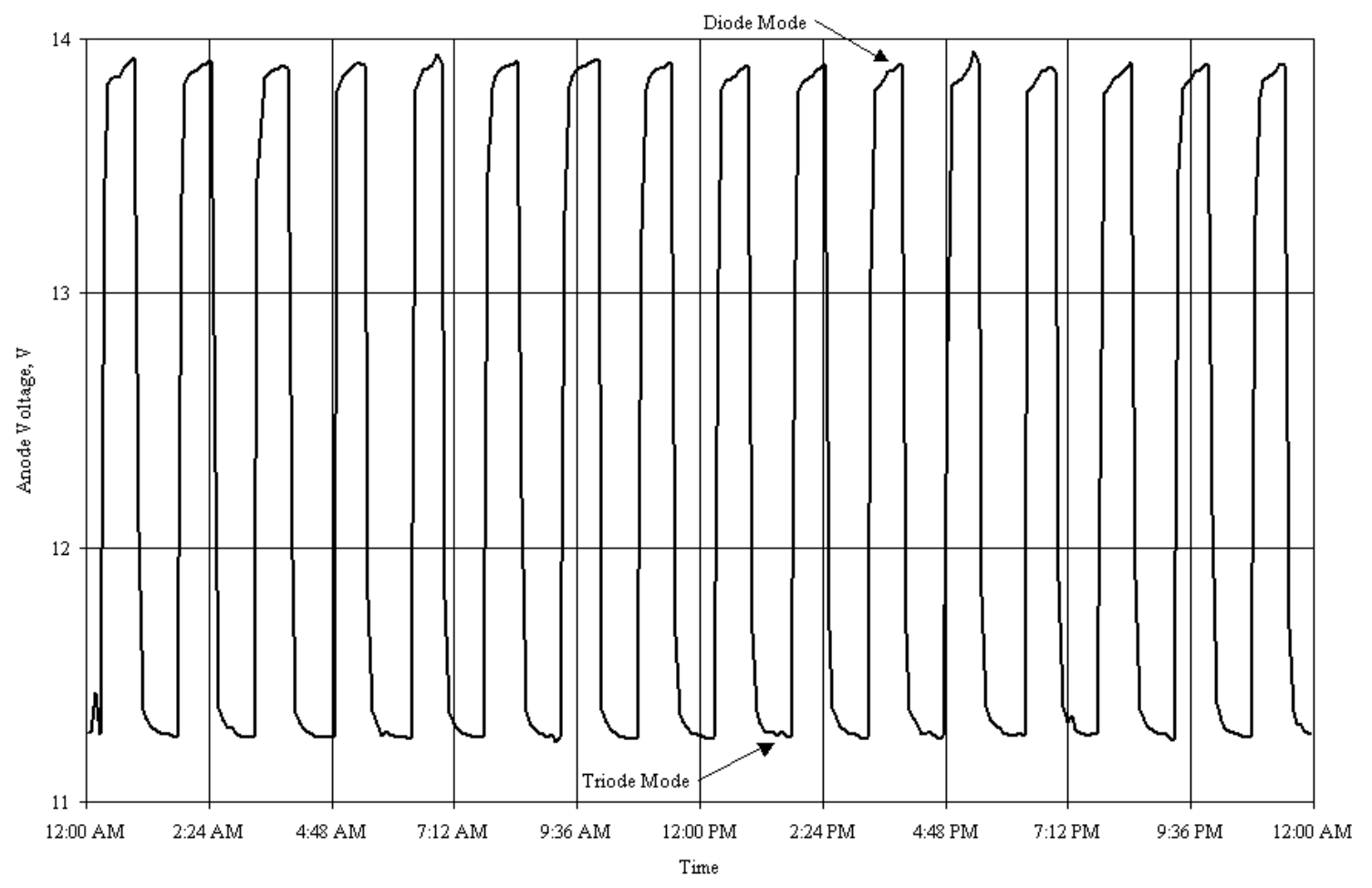

Figure 11 - HCA006 Anode Voltage After Approximately 3,000 Hours of Operation

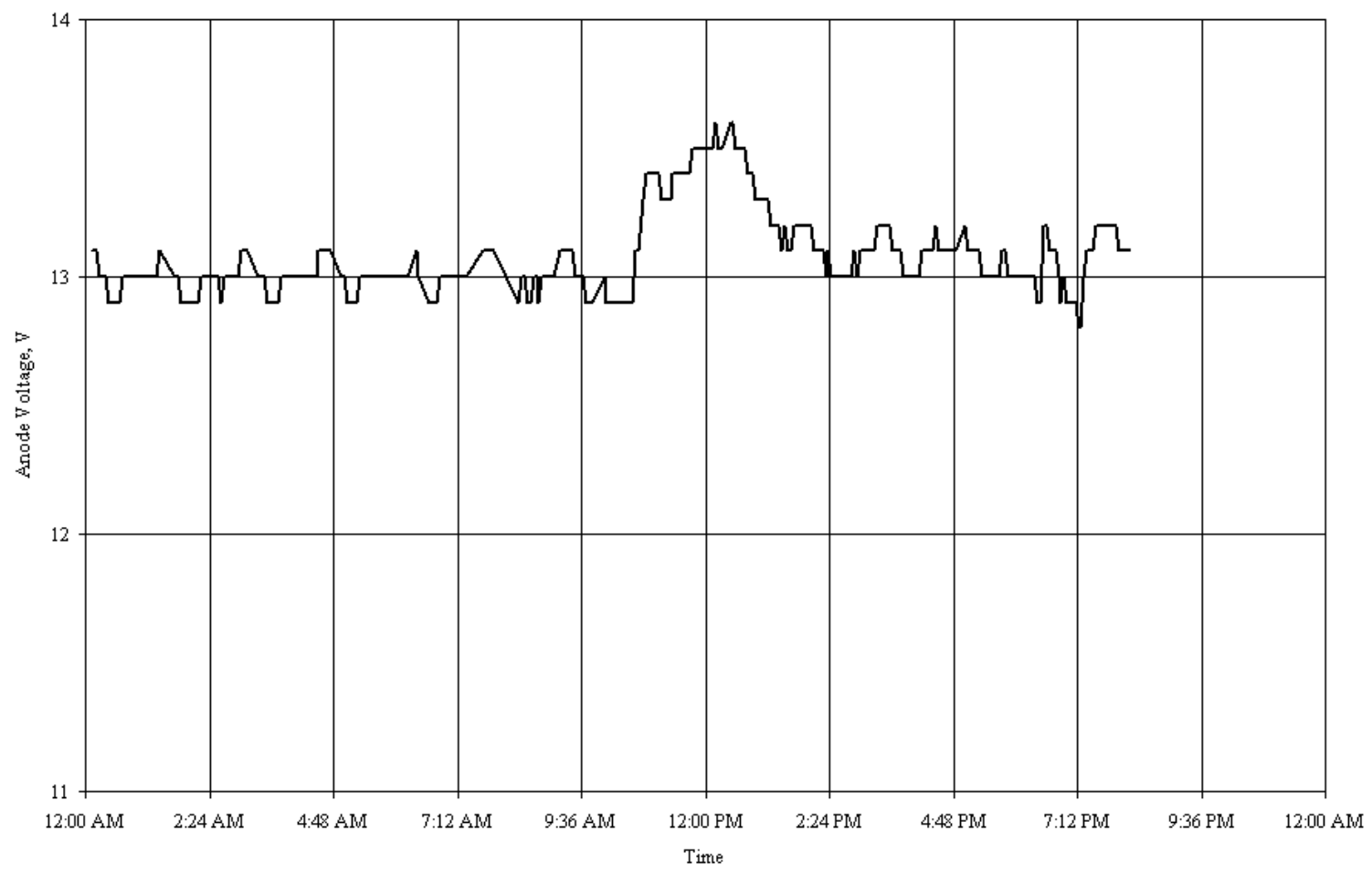

Figure 12 - PCU2 Anode Voltage After Approximately 3,000 Hours of Operation 


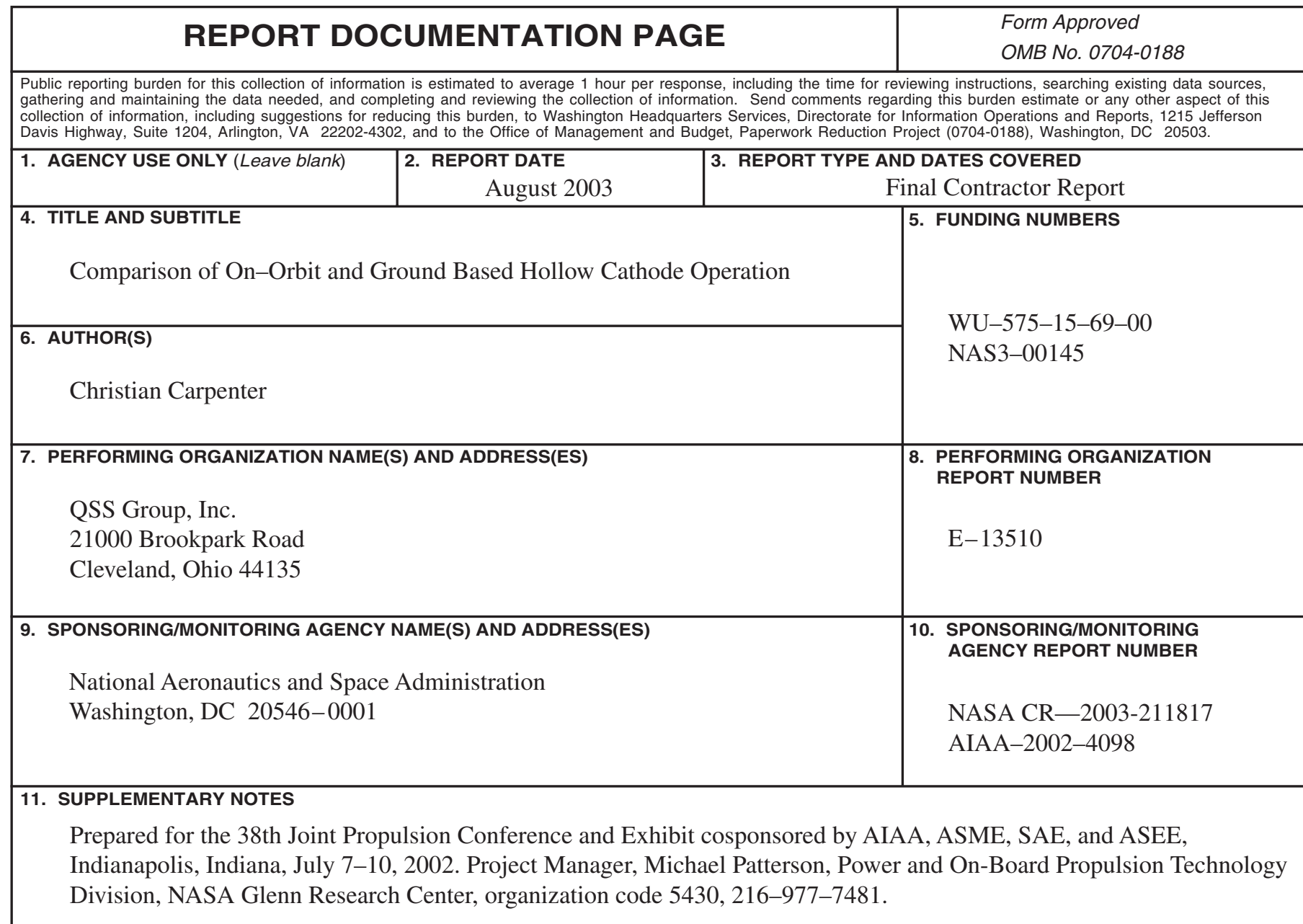

12a. DISTRIBUTION/AVAILABILITY STATEMENT

12b. DISTRIBUTION CODE

Unclassified - Unlimited

Subject Category: 20

Distribution: Nonstandard

Available electronically at http://gltrs.grc.nasa.gov

This publication is available from the NASA Center for AeroSpace Information, 301-621-0390.

13. ABSTRACT (Maximum 200 words)

The Plasma Contactor Units (PCUs) were developed at NASA Glenn Research Center (GRC) and Boeing for charge control on board the International Space Station (ISS). Since the first ignition of a PCU on 10/16/2000 over 3,900 hours of operation have been demonstrated on a single unit. In order to guarantee that the PCUs' hollow cathode assemblies (HCAs), which emit the electrons used for charge control, would satisfy the life requirement of 18,000 hours, a ground based hollow cathode life test program was initiated at GRC. The life test program aimed at 27,000 hours of operation on a single unit to demonstrate the industry standard 1.5 times operational life requirement. As of this printing, over 18,000 hours of operation have been accumulated on a single hollow cathode. By comparing the data received from the on-orbit HCAs to the data obtained for the life test cathodes, a comparison may be drawn to determine if the on-orbit HCAs are operating normally, with a final goal of predicting lifetime. Based on the data taken thus far, it can be concluded that the on-orbit HCAs are operating within their design specifications.

14. SUBJECT TERMS

Electron plasma; Hollow cathodes; Space plasmas; International Space Station

\begin{tabular}{|c|c|c|}
\hline $\begin{array}{c}\text { 17. SECURITY CLASSIFICATION } \\
\text { OF REPORT } \\
\text { Unclassified }\end{array}$ & $\begin{array}{c}\text { 18. SECURITY CLASSIFICATION } \\
\text { OF THIS PAGE } \\
\text { Unclassified }\end{array}$ & $\begin{array}{c}\text { 19. SECURITY CLASSIFICATION } \\
\text { OF ABSTRACT } \\
\text { Unclassified }\end{array}$ \\
\hline
\end{tabular}

NSN 7540-01-280-5500

Standard Form 298 (Rev. 2-89)

Prescribed by ANSI Std. Z39-18 298-102 

